\title{
THE EFFECT OF A SYNTHETIC ANALOGUE OF PYROPHOSPHATE ON CALCIUM, MAGNESIUM AND PHOSPHORUS HOMEOSTASIS IN SHEEP
}

\author{
T. Matsui ${ }^{1}$, T. Kawabata, T. Harumoto and H. Yano ${ }^{2}$
}

Faculty of Agriculture, Shimane University, Matsue-shi 690, Japan

\begin{abstract}
Summary
Three female sheep were daily administered a pyrophosphate analogue, disodium 1-hydroxyethylidene-1, 1-bisphosphonate (HEBP) at the level of $4 \mathrm{mg} / \mathrm{kg}$ body weight. HEBP largely suppressed bone resorption, which was indicated by the reduction in plasma free hydroxyproline concentration and in calcium mobilization rate during the intravenous infusion of disodium ethylenediaminetetraacetate (EDTA). Contrary to the suppression of bone resorption, plasma total-calcium, magnesium and phosphorus concentrations were not changed by HEBP administration. These results suggest that bone mineral crystals play a meaningless role on calcium, magnesium and phosphorus homeostasis in ruminants if they are fed adequate amounts of these minerals. Plasma magnesium and phosphorus concentrations were not significantly changed after feeding. However, plasma total-calcium was decreased after feeding in both periods and the reduction seemed to be remarkable in the HEBP-treated period. Infusion of EDTA more remarkably reduced plasma ionized calcium concentration in the HEBPtreated than in the untreated period and the recovery of ionized calcium was retarded by HEBP administration. These results suggest that calcium release from bone is necessary for maintenance of plasma calcium when animals rapidly lose calcium.
\end{abstract}

(Key Words: Bisphosphonate, Calcium, Phosphorus, Magnesium, Bone, Sheep)

\section{Introduction}

Calcium (Ca), magnesium $(\mathrm{Mg})$ and phosphorus (P) are important components of the hard tissues. Approximately, $99 \%$ of $\mathrm{Ca}, 70 \%$ of $\mathrm{Mg}$ and $80 \%$ of $\mathrm{P}$ in the whole body of adult ruminants locate in bones and teeth. It is recognized that $\mathrm{Ca}$ and $\mathrm{P}$ are constantly deposited and removed in the skeletal tissue, which plays important roles on $\mathrm{Ca}$ and $\mathrm{P}$ metabolism in mammals including ruminants (Georgievskii, 1982). Bone $\mathrm{Mg}$ is also exchangeable to $\mathrm{Mg}$ in extracellular fluid and is postulated to contribute, to some extent, to $\mathrm{Mg}$ homeostasis in ruminants (Simesen et al., 1964; House and Campen, 1971). Almost all of these results, on the other hand, have been obtained by kinetics studies and there are few evidences that directly show the importance of bony tissue to keep $\mathrm{Ca}, \mathrm{Mg}$ and $\mathrm{P}$ homeostasis in ruminants.

It is suggested that mineral exchange between

${ }^{1}$ Address reprint requests to Dr. T. Matsui, Faculty of Agriculture, Shimane University, Matsue-shi 690, Japan.

${ }^{2}$ Faculty of Agriculture, Kyoto University, Kyoto-shi 606, Japan.

Received March 6, 1991

Accepted February 1, 1992 bone mineral crystals and extracellular fluid is regulated by pyrophosphate, i. e., pyrophosphate is adsorbed on the surface of bone mineral crystals to interfere with the precipitation and dissolution of minerals, and enzymatic degradation of pyrophosphate is involved in mineral movement (Fleisch et al., 1966a; Fleisch et al., 1966b). Although pyrophosphate administration, itself, dose not affect bone metabolism in vivo because of its rapid hydrolysis, some pyrophosphate analogues, which are resistant to the hydrolysis, have been developed (Fleisch, 1985). These analogues are now known to be highly active in the skeletal tissue of laboratory animals and have little toxicity.

The objectives of this study is to clarify the importance of bone in $\mathrm{Ca}, \mathrm{Mg}$ and $\mathrm{P}$ homeostasis by measuring these mineral concentrations in plasma during the suppression of bone metabolism by the administration of a pyrophosphate analogue.

\section{Materials and Methods}

Three female sheep, aged 1 year and weighing about $28 \mathrm{~kg}$, were used. Each sheep was housed in a separate pen and fed the diet shown in table 1 , at a level of $1.1 \%$ of body weight at $12-\mathrm{hr}$ 
TABLE 1. DIET COMPOSITION

\begin{tabular}{lc}
\hline Ingredient/Composition & Percentage \\
\hline Ingredients : & \\
Timothy hay & 60.0 \\
Wheat bran & 20.0 \\
Barley grain & 18.5 \\
Sodium chloride & 1.0 \\
Calcium carbonate & 0.5 \\
\hline Composition : & \\
Calcium & 0.51 \\
Magnesium & 0.29 \\
Phosphorus & 0.44 \\
\hline
\end{tabular}

intervals. Water was available at all time.

A pyrophosphate analogue, disodium 1hydroxyethylidene-1, 1-bisphosphonate (HEBP; Procter and Gamble Co, Norwich, New York, U.S.A.) was dissolved in sterilized saline and adjusted $\mathrm{pH}$ to 7 by hydrochloric acid. The HEBP solution was intramuscularly injected at $4 \mathrm{mg} / \mathrm{kg}$ body weight for 41 days when animals were given morning feed.

After a 5-day preliminary period, following 3 experiments were conducted in this study; (1) blood were collected from the jugular vein before the administration of HEBP and at 3-day intervals for 21 days during the administration at $4 \mathrm{hr}$ after morning feeding. Plasma total-Ca, $\mathrm{Mg}, \mathrm{P}$ and free hydroxyproline (Hyp) concentrations were measured in these blood samples. (2) two days before and 23 days after the initiation of HEBP administration, sheep were sampled blood just before, and 2, 4, 6 and $8 \mathrm{hr}$ after feeding. Plasma total-Ca, $\mathrm{Mg}$ and $\mathrm{P}$ concentrations were measured in these blood samples. (3) twenty five days before and 38 days after the initiation of HEBP administration, every sheep was fitted with bilateral siliconized jugular catheters. Two days after the catheterization, animals were infused disodium ethylenediaminetetraacetate (EDTA) through a catheter at $4.38 \mu \mathrm{mol} / \mathrm{kg}$ body weight/ min for $60 \mathrm{~min}$ by a peristaltic pump. The solution was prepared to contain $2 \%$ EDTA in saline and was adjusted $\mathrm{pH}$ to 7.4 by hydrochloric acid. The solution was sterilized in an autoclave $\left(121^{\circ} \mathrm{C}, 20 \mathrm{~min}\right) 1 \mathrm{hr}$ before the infusion. Blood samples were taken through the other catheter prior to, and $15,30,45,60,75,90$,
$120,150,180$ and $240 \mathrm{~min}$ after the initiation of EDTA infusion. And plasma total-Ca and ionized $\mathrm{Ca}$ concentration were measured. The rate of $\mathrm{Ca}$ mobilization was calculated according to the method of Contreras et al. (1982) modified by Terashima et al. (1988).

Plasma total- $\mathrm{Ca}$ and $\mathrm{Mg}$ concentrations were determined by an atomic absorption spectrophotometry. Ionized $\mathrm{Ca}$ concentration was measured by an ionic meter (Sera-250, Horiba Ltd. Japan) and phosphorus concentration was analyzed by the method of Fiske and Subbarow (1925). Plasma free Hyp was measured by the method of Bergman and Loxley (1961).

The statistical significance were calculated by a paired t-test.

\section{Results}

Figure 1 shows changes of total-Ca, $\mathrm{Mg}, \mathrm{P}$ and free Hyp concentrations in plasma after the initiation of HEBP administration with time. Plasma Hyp concentration began to decrease 3 days after the initiation of HEBP administration and reached to the approximately half level of the untreated period 6 days after the initiation of HEBP administration. Then the level of plasma

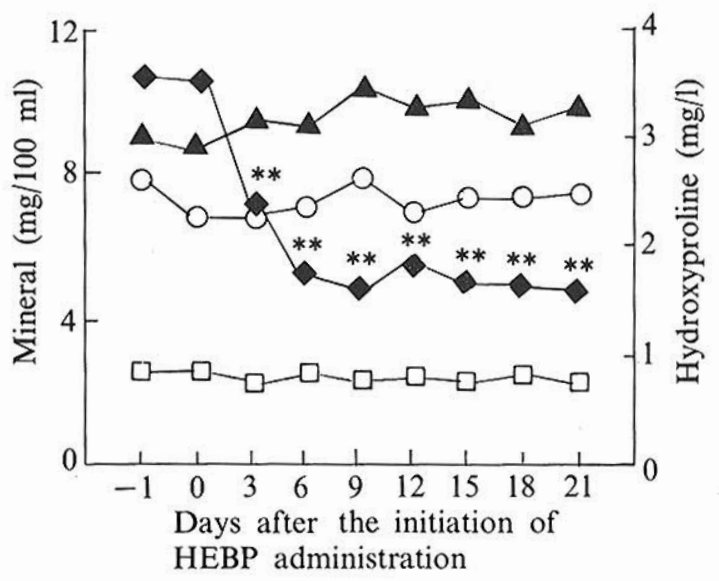

Figure 1. The effect of disodium 1-hydroxyethylidene-1, 1-bisphosphonate administration on plasma calcium ( $\boldsymbol{\Delta})$, magnesium $(\square)$, phosphorus (O) and free hydroxyproline $(\Delta)$ concentrations in sheep.

** Significantly $(p<0.01)$ different from the value before the administration ( -1 day). 
Hyp was not changed till the end of the experiment. Contrary to the changes in plasma Hyp, plasma total-Ca, $\mathrm{Mg}$ and $\mathrm{P}$ concentrations were not changed by HEBP administration.

Figure 2 shows the changes of plasma total and ionized $\mathrm{Ca}$ concentrations by the intravenous infusion of EDTA in the untreated and the HEBP-treated periods. EDTA infusion decreased plasma ionized $\mathrm{Ca}$ level of which recovery commenced at $30 \mathrm{~min}$ after the infusion in both periods. The reduction in ionized $\mathrm{Ca}$ concentration, however, was more remarkable in the

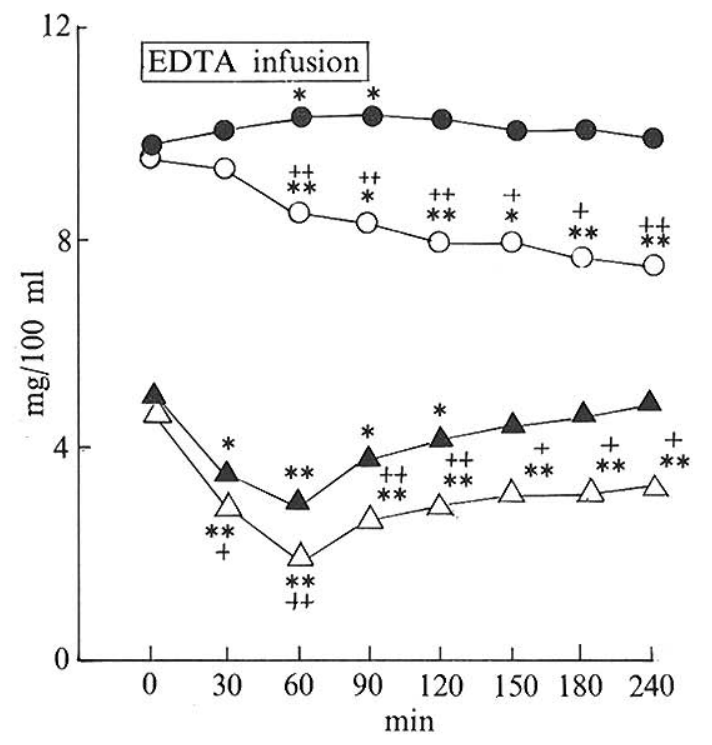

Figure 2. Changes in plasma total and ionized calcium concentrations during the intravenous infusion of disodium ethylenediaminetetraacetate (EDTA) in periods when sheep were or were not administered disodium 1-hydroxyethylidene-1, 1-bisphosphonate (HEBP).

$O$ : total calcium in the HEBP-treated period.

- : total calcium in the untreated period. $\triangle$ : ionized calcium in the HEBP-treated period.

$\Delta$ : ionized calcium in the untreated period.

Significantly (* $\mathrm{p}<0.05, * * \mathrm{p}<0.01)$ different from the value before EDTA infusion. Significantly ( $p<0.05,{ }^{+} p<$ 0.01 ) different from the value of the untreated period.
HEBP-treated period than in the untreated period during EDTA infusion and the recovery of ioniz ed $\mathrm{Ca}$ was retarded by HEBP administration after EDTA infusion. Consequently, plasma ionized $\mathrm{Ca}$ concentration perfectly recovered in sheep which were not administered HEBP but was approximately $40 \%$ less in the HEBP-treated animals than in the untreated ones $240 \mathrm{~min}$ after the initiation of EDTA infusion.

Plasma total-Ca concentration was slightly increased by EDTA infusion in the untreated period but was gradually decreased in the HEBPtreated period till the end of the experiment. Ca mobilization rates, which were calculated from the changes in plasma total and ionized Ca levels, were $228 \pm 18$ and $176 \pm 11$ (mean $\pm \mathrm{SE}$ ) $\mathrm{mg} / \mathrm{hr}$ in the untreated and the HEBP-treated periods, respectively. There was a significant $(p<0.01)$ difference between these values.

Table 2 shows changes in plasma total-Ca, $\mathrm{Mg}$ and $\mathrm{P}$ concentrations after feeding in the untreated and the HEBP-treated periods. There were no significant changes in plasma $\mathrm{Mg}$ and $\mathrm{P}$ concentrations after feeding in both periods and HEBP administration did not affect plasma $\mathrm{Mg}$ and $\mathrm{P}$ concentrations after feeding. On the other hand, plasma $\mathrm{Ca}$ concentration was significantly $(\mathrm{p}<0.05)$ decreased in the untreated period $4 \mathrm{hr}$ after feeding and in the HEBP-treated period 2 and $4 \mathrm{hr}$ after feeding and the reduction in plasma $\mathrm{Ca}$ seemed to be remarkable in the HEBP-treated period.

\section{Discussion}

Administration of HEBP strikingly decreased plasma free Hyp concentration which is thought to be an index of bone resorption (Dull and Hennemann, 1963). In addition, Ca mobilization was significantly suppressed by HEBP during EDTA infusion. These results indicate that HEBP largely interferes with bone resorption in sheep. The suppressive effect of HEBP on bone resorption was also found in various mammals (Gasser et al., 1972; Reynolds et al., 1972; Guncaga et al., 1974).

Administration of HEBP lowered plasma Hyp concentrations to more than $50 \%$ of the value in the untreated period. The reduction of $\mathrm{Ca}$ mobilization rate, however, was not so remarkable as the decrease in plasma Hyp. When EDTA 
MATSUI ET AL.

TABLE 2. THE EFFECT OF HEBPa ADMINISTRATION ON PLASMA MINERAL CONCENTRATIONS AFTER FEEDING IN SHEEP

\begin{tabular}{|c|c|c|c|c|c|}
\hline & \multirow{2}{*}{$\begin{array}{l}\text { Before } \\
\text { feeding }\end{array}$} & \multicolumn{4}{|c|}{ Hours after feeding } \\
\hline & & 2 & 4 & 8 & 12 \\
\hline & & \multicolumn{4}{|c|}{ Calcium $(\mathrm{mg} / 100 \mathrm{ml})$} \\
\hline Untreated & $8.87 \pm 0.33$ & $8.32 \pm 0.49$ & $8.35 \pm 0.27 *$ & $8.58 \pm 0.48$ & $8.20 \pm 0.42$ \\
\hline Administered & $8.80 \pm 0.45$ & \multicolumn{4}{|c|}{ Magnesium (mg/100 ml) } \\
\hline Untreated & $2.07 \pm 0.22$ & $2.06 \pm 0.20$ & $2.05 \pm 0.16$ & $2.08 \pm 0.18$ & $2.04 \pm 0.14$ \\
\hline Administered & $2.30 \pm 0.12$ & $2.10 \pm 0.08$ & $\begin{array}{l}2.20 \pm 0.07 \\
\text { Phosphorus }\end{array}$ & $\begin{array}{l}2.29 \pm 0.07 \\
\mathrm{mg} / 100 \mathrm{ml})\end{array}$ & $2.32 \pm 0.18$ \\
\hline Untreated & $7.45 \pm 0.32$ & $7.68 \pm 0.64$ & $7.38 \pm 0.51$ & $6.80 \pm 0.49$ & $7.01 \pm 0.40$ \\
\hline Administered & $6.99 \pm 0.60$ & $6.98 \pm 0.27$ & $6.56 \pm 0.34$ & $6.78 \pm 0.59$ & $6.72 \pm 0.39$ \\
\hline
\end{tabular}

Values are means $\pm \mathrm{SE}(\mathrm{n}=3)$.

* Significantly $(\mathrm{p}<0.05)$ different from the value before feeding.

a Disodium 1-hydroxyethylidene-1, 1-bisphosphonate.

is infused, $\mathrm{Ca}$ is possibly mobilized from not only bone but also some soft tissues. Furthermore, $\mathrm{Ca}$ can be released from the skeletal tissue without bone resorption. It is postulated that there is an easily exchangeable $\mathrm{Ca}$ pool between bone matrix, where minerals are precipitated as crystals, and bone cells including osteoblasts and osteocytes. The $\mathrm{Ca}$ pool is named bone fluid which is thought to be owing to a rapid $\mathrm{Ca}$ movement into general extracellular fluid (Talmage, 1970). Calcium in bone fluid possibly enters general extracellular fluid when plasma ionized Ca level is decreased by EDTA infusion. On the other hand, plasma free Hyp is suggested to be increased by collagen degradation in bone matrix (Dull and Hennemann, 1963) which is involved in $\mathrm{Ca}$ release from bone crystal. It seems reasonable that HEBP administration more remarkably decreases plasma Hyp than Ca mobilization rate measured by EDTA infusion.

Plasma total-Ca, $\mathrm{Mg}$ and $\mathrm{P}$ concentrations were not changed by HEBP administration though bone resorption was obviously suppressed. These results suggest that sheep can keep homeostasis of these minerals notwithstanding the striking suppression of bone resorption if they are fed adequate amounts of minerals. The suppression of bone resorption is thought to be compensated for these mineral metabolisms in the alimentary tract and the bone fluid, and, to the less extent, in the kidney. In addition, pyrophosphate analogues are reported to suppress not only bone resorption but also bone formation (Gasser et al., 1972). The suppression of bone anabolism may also affect maintenance of mineral homeostasis during HEBP administration.

Contrary to changeless in plasma Ca concentration during HEBP administration, HEBP promotes the reduction of ionized $\mathrm{Ca}$ level during EDTA infusion. These results indicate that $\mathrm{Ca}$ release from bone mineral crystals is necessary for maintenance of plasma $\mathrm{Ca}$ when $\mathrm{Ca}$ is rapidly lost. Furthermore it may not be impossible that a mineral homeostasis is disturbed by HEBP administration when sheep suffer a mineral deficiency. In fact, $\mathrm{Mg}$ deficiency induced severer hypomagnesemia in HEBP-treated sheep than in intact ones (Matsui et al., 1991). There are contradictory reports about the effect of HEBP administration on plasma $\mathrm{Ca}$ and $\mathrm{P}$ concentrations. Talmage et al. (1974) reported that HEBP administration at $40 \mathrm{mg} / \mathrm{kg}$ body weight/day did not affect serum $\mathrm{Ca}$ and $\mathrm{P}$ concentration in rats. On the other hand, Rosenblum (1974) described that dose of $2.5 \mathrm{mg} / \mathrm{kg}$ body weight/day HEBP did not affect serum Ca concentration but increased serum $P$ in rabbits. The higher dose of HEBP administration was reported to increase $\mathrm{Ca}$ balance and plasma $\mathrm{Ca}$ in rats (Gasser et al., 1972). It is not clear why the contradiction occurs but physiological conditions of used animals, doses of HEBP and nutritional status of minerals might affect the response to HEBP administration.

In monogastric animals, it has been thought that the influx of $\mathrm{Ca}$ from the gut into extra- 
cellular fluid, i e., Ca absorption, is not constant and it may not be sufficient to maintain plasma $\mathrm{Ca}$ concentration during a period between meals. The gradual reduction in $\mathrm{Ca}$ absorption would stimulate bone resorption through the increase in the secretion of parathyroid hormone (Shaafsma, 1988). Furthermore it is suggested that postprandial stimulation of calcitonin secretion inhibits bone resorption and prevents hypercalcemia induced by the increase in $\mathrm{Ca}$ absorption after feeding (Munson, 1976).

The apparent absorption of Ca mainly occurs in the forestomach of ruminants (Grace et al., 1974). It is possible to consider that the rate of $\mathrm{Ca}$ absorption is not constant and that bone plays an important role on maintenance of $\mathrm{Ca}$ homeostasis which is apt to be disturbed by feeding in ruminants as same as in monogastric animals. In this study, plasma $\mathrm{Ca}$ level was decreased after feeding in the untreated period. The results may support that there is a mechanism to prevent hypercalcemia induced by feeding in ruminants as same as in monogastric animals. On the other hand, plasma $\mathrm{Ca}$ tended to be remarkably decreased in the HEBP-treated period, which indicated that the postprandial reduction in plasma $\mathrm{Ca}$ is not related to the suppression of bone resorption. It is, furthermore, suggested that the reduction in plasma $\mathrm{Ca}$ is not owing to the increasing calcitonin secretion in sheep because the hypocalcemic action of calcitonin is reported to be diminished by HEBP administration in rats (Talmage et al., 1974).

Milhaud et al. (1972) reported that plasma $\mathrm{Ca}$ tended to be decreased during the feeding period in intact rats but was increased in thyroidectomized ones. It was shown, however, that the decrease in plasma $\mathrm{Ca}$ during feeding was not reversed by thyroidectomy (Talmage et al., 1975). It is proposed from the latter report and the present study that a factor or factors other than calcitonin may induce the postprandial reduction in plasma $\mathrm{Ca}$ concentration without changing bone metabolism. Further study is needed to clarify the mechanism inducing the postprandial fall in plasma $\mathrm{Ca}$.

\section{Acknowledgements}

The authors are grateful to Dr Tsutomu Fujihara, Faculty of Agriculture, Shimane Uni- versity for his kind advice in the preparation of the manuscript.

\section{Literature Cited}

Bergman, I. and R. Loxley. 1963. Two improved and simplified methods for the spectrophotometric determination of hydroxyproline. Anal. Chem. 35 :1961-1965.

Contreras, P. A., R. Manston and B. F. Sansom. 1982. Calcium mobilisation in hypomagnesaemic cattle. Res. Vet. Sci. 33:10-16.

Dull, T. A. and P. H. Hennemann. 1963. Urinary hydroxyproline as an index of collagen turnover in bone. N. Engl. J. Med. 268:132-134.

Fiske, C. M. and Y. Subbarow. 1925. The colorimetric determination of phosphorus. J. Biol. Chem. 66: 375-382.

Fleisch, H., J. Maerki and R. G. G. Russel. 1966a. Effect of pyrophosphate on dissolution of hydroxyapatite and its possible importance in calcium homeostasis. Proc. Soc. Exp. Biol. Med. 122:317 -320 .

Fleisch, H., R. G. G. Russel and F. Straumann. 1966b. Effect of pyrophosphate on hydroxyapatite and its implications in calcium homeostasis. Nature (London) 212:901-903.

Fleisch, H. 1985. Chemistry and mechanisms of action of bisphosphonates. In: S. Garattini (ed.). Bone resorption metastasis, and diphosphonates. pp. 33 -40. Raven Press, New York.

Gasser, A. B., D. B. Morgan, H. A. Fleisch and L. J. Richelle. 1972. The influence of two diphosphonates on calcium metabolism in the rat. Clin. Sci. 43:31-45.

Georgievskii, V. I. 1982. The physiological role of macroelements. In: V. I. Georgievskii, B. N. Annenkov and V. T. Samokhin (eds.). Mineral nutrition of animals. pp. 91-170, Butterworths, London.

Grace, N. D., M. J. Ulyatt and J. C. Macrae. 1974. Quantitative digestion of fresh herbage by sheep. 3. The movement of $\mathrm{Mg}, \mathrm{Ca}, \mathrm{P}, \mathrm{K}$ and $\mathrm{Na}$ in the digestive tract. J. Agric. Sci. Camb. 82:321-330.

Guncaga, J., Th. Lauffenburger, C. Lentner, M. A. Dambacher, H. G. Hass, H. Fleisch and A. J. Olah. 1974. Diphosphonate treatment of Paget's disease of bone. A correlated metabolic, calcium kinetic and morphometric study. Horm. Metab. Res. 6:62-69.

House, W. A. and D. V. Campen. 1971. Magnesium metabolism of sheep fed different levels of potassium and citric acid. J. Nutr. 101:1483-1492.

Matsui, T., T. Kawabata, T. Fujihara and T. Harumoto. 1991. The relationship between magnesium homeostasis and bone metabolism in sheep. In : M. Wan Zahari, Z. Ahmad Tajuddin, N. Abdullah and $\mathrm{H}$. K. Wong (eds.). Proceedings of the third international symposium on the nutrition of herbivores. pp. 2. The Malaysian Society of Animal 


\section{MATSUI ET AL.}

Production, Serdang, Malaysia.

Milhaud, G., A. M. Perault-Staub and J. F. Staub. 1972. Diurnal variation of plasma calcium and calcitonin function in the rat. J. Physiol. 222: 559- 567.

Munson, P. L. 1976. Physiology and pharmacology of thyrocalcitonin. In : G. D. Aurbach (ed.). Handbook of physiology, section 7, vol. 7 pp. 443-464. Waverly Press, Baltimore.

Reynolds, J. J., C. Minkin, D. B. Morgan, D. Spycher and H. Fleisch. 1972. The effect of two diphosphonates on the resorption of mouse calvaria in vitro. Calcif. Tissue Res. 10:302-313.

Rosenblum, I. Y. 1974. The effects of disodium ethan1-hydroxy-1, 1-diphosphonate on bone and serum chemistry in rabbits. Calcif. Tissue Res. 16:145152.

Shaafsma, G. 1988. Calcium in extracellular fluid : homeostasis. In: B. E. C. Nordin (ed.). Calcium in human biology. pp. 241-259. Springer-Verlag, Berlin.
Simesen, M. G., T. A. Rogers, T. Lunaas and J. R. Luick. 1964. Plasma-Mg 28 disappearance in the bovine. Proc. Symp. Radioisot. Anim. Nutr. Physiol. pp. 721-736. International Atomic Energy Agnecy, Vienna.

Talmage, R. V. 1970. Morphological and physiological considerations in a new concept of calcium transport in bone. Am. J. Anat. 129:467-476.

Talmage, R. V., J. J. B. Anderson and J. W. Kennedy. 1974. Separation of the hypocalcemic and hypophosphatemic actions of calcitonin with disodium ethan-1-hydroxy-1, 1-diphosphonate. Endocr. 94: 413-418.

Talmage, R. V., J. H. Roycroft and J. J. B. Anderson. 1975. Daily fluctuations in plasma calcium, phosphate and their radionuclide concentrations in the rats. Calcif. Tissue Res. 17:91-102.

Terashima, Y., S. Matsunobu, T. Yanagisawa and $\mathrm{H}$. Itoh. 1988. Calcium mobilization in hypomagnesemic wethers fed on a low magnesium and/or high potassium diet. Jpn. J. Zootech. Sci. 59:75-81. 